\title{
The effect of heather fragmentation and mixed grazing on the diet of sheep Ovis aries and red deer Cervus elaphus
}

\author{
Paloma CUARTAS, Iain J. GORDON ${ }^{1}$, Alison J. HESTER, \\ F. Javier PÉREZ-BARBERÍA, and Ian A. R. HULBERT ${ }^{2}$
}

Cuartas P., Gordon I. J., Hester A. J., Pérez-Barbería F. J. and Hulbert I. A. R. 2000. The effect of heather fragmentation and mixed grazing on the diet of sheep Ovis aries and red deer Cervus elaphus. Acta Theriologica 45: 309-320.

The effects of vegetation fragmentation and mixed grazing (ie mono- or multi-species animal group) on the diet composition of sheep and red deer grazing mosaics of grassland and heather moorland was studied, using faecal cuticle analysis, in two experimental sites in Scotland during the summer of 1992 and 1993. On Site A, the influence of grassland fragmentation on diet composition was estimated for sheep and deer grazing together in plots where the grassland (20\% of the area) was artificially distributed as one large, four medium or twelve small patches within a homogeneous moorland matrix ( $80 \%$ of the area). On Site B, differences in diet composition between animals grazing within mono-species (sheep or deer) and multi-species groups (sheep and deer together) were examined for each animal species. In this site all plots used contained a similar natural mosaic pattern of grass and heather (ie similar mixtures of patch sizes, with about $20 \%$ grass and $80 \%$ heather cover). On Site A, the proportions of grass in the diet of sheep $(73 \%)$ and deer $(27 \%)$ were found to be similar across all levels of grass fragmentation. A significant interaction was found between the pattern of fragmentation and the three periods in which the experiment was carried out. On Site B in 1992, sheep had more grass in their diet than did deer (52\% vs $46 \%$ ), and the diets of both sheep and deer responded in the same fashion when the species were grazing in mono- or multi-species groups. The consumption of grass decreased in both species throughout the period studied. Deer showed no change in the proportion of grass in their diet in the presence or absence of sheep in 1992 (deer $48 \%$ vs sheep 50\%). But on Site B in 1993, the diet of sheep contained a significantly higher proportion of grasses when they were grazing with red deer $(52 \%)$ than when they were grazing alone $(38 \%)$ These results suggest that on grassland/heather moorland mosaics sheep may suffer intraspecies competition to a greater extent than do red deer, particularly where grass is in relatively low supply.

Instituto Pirenaico de Ecología, Apdo 64, 22700, Jaca (Huesca), Spain (PC); The Macaulay Land Use Research Institute, Craigiebuckler, Aberdeen, AB15 8QH, U.K. (IJG, AJH, FJP-B); Centre for Ecology and Hydrology, Hill of Brathens, Banchory, Kincardineshire, AB31 4BY, U.K. (IARH)

Key words: diet composition, herbivory faecal analysis, vegetation fragmentation, competition

\footnotetext{
${ }^{1}$ Author to whom correspondence should be sent

${ }^{2}$ Present address: Hill and Mountain Research Unit, The Scottish Agriculture College, Kirkton Farm, Crainlarich, FK20 8RU, U.K.
} 


\section{Introduction}

Plant communities are generally distributed as patches across rangelands and vary, spatially and temporally, in the quantity and quality of forage they offer to herbivores (McNaughton 1991). Herbivores respond to this fragmented distribution of resources by being selective in their feeding behaviour across many spatial scales (Senft et al. 1987, McNaughton 1991) which, in turn, feeds back to affect the animal distribution (Gwynne and Bell 1968, Jarman 1974) and vegetation (Wiens 1985).

In Scotland, about a quarter of the total land surface is covered by moorlands dominated by heather Calluna vulgaris (Welch 1984) with patches of grass of varying size intermixed with heather. This fragmented vegetation structure is a consequence of topography, land management practices and grazing pressures mainly from sheep Ovis aries Linnaeus, 1758 and to a lesser extent from native wild red deer Cervus elaphus Linnaeus, 1758 (Sydes and Miller 1988). Both sheep and red deer are mixed feeders (Hofmann 1989) although sheep concentrate their grazing activity on grass-dominated areas within moorlands, whereas red deer have a greater tendency to include browse in their diet (Colquhoun 1970, Bullock 1985, Gordon 1989, Fraser and Gordon 1997). This could be due to differences in body size between species. Larger species are able to use lower quality but more abundant vegetation because of their ratio of energy requirements $\left(\mathrm{BM}^{0.75}\right)$ to gut volume (BM ${ }^{1}$ ) (Demment 1982, Van Soest 1996). Previous research has shown that the size and distribution of the grass patches influences the vegetation community use of sheep more than red deer (Clarke et al. 1995a, Hester et al. 1999), however, little is known about the effects of mosaic vegetation patterns on the diet of the two species.

As a consequence of the overall similarity of vegetation community preference, Osborne (1984) concluded that sheep and red deer should compete for preferred resources (ie grasses) when they graze together. In the presence of sheep, red deer may thus be forced to utilize heather to a greater extent as a consequence of the smaller sheep being better able to forage more efficiently on the shorter swards (Illius and Gordon 1987).

In this paper, two separate experiments were used to test: (1) to what extent the fragmentation of grass patches in heather moorland influences the diet of sheep and red deer, and (2) whether the two species of herbivore would select different diets when grazing together as compared to when grazing alone. In the second case, the hypothesis was that the preferred category of vegetation in the diet of deer when grazing alone will decrease when they grazed with sheep. This difference in diet composition would be expected to increase when the sward height of the grass decreases, as a consequence of grass being depleted by the grazing activity of both species.

\section{Material and methods}

The study was conducted in the summers of 1992 and 1993 at two experimental sites at the Macaulay Land Use Research Institute's Glensaugh Research Station in north-east Scotland, U.K. One 
of the sites (Site A) comprised 3 different sizes of grass patch sown into a homogeneous area of heather moorland. The other site (Site B) comprised a natural mosaic of grass and heather. In both sites the ratio of grass to heather cover was approximately 1:4.

\section{Study sites and experimental design}

\section{Site A}

The response of sheep and red deer to increasing fragmentation of vegetation was studied on Site A, which comprised 15 ha of heather moorland with some natural patches of bilberry Vaccinium myrtillus and bracken Pteridium aquilinum. The area was fenced with deer proof fencing to produce two blocks of three 2.5-ha plots each. In each plot approximately 0.5 ha of grass (a mix of Agrostis capillaris and Festuca rubra) was sown to provide three fragmentation patterns, namely: (1) one square grass patch $(70 \times 70 \mathrm{~m})$, (2) four square grass patches (each $35 \times 35 \mathrm{~m}$ ), (3) twelve square grass patches (each $20 \times 20 \mathrm{~m}$ ) in a regular pattern. A detailed description of the experimental site and blocks and treatment arrangement is given in Clarke et al. (1995a).

The experimental design consisted of three mixed groups of 15 adult Scottish Blackface ewes and 7 yearling red deer hinds. Animal density was equivalent to 10 sheep/ha in the plots. The ratio of deer to sheep was determined by assuming that a yearling hind consumed approximately 1.5 times as much dry matter as an adult ewe (Milne et al. 1978). Both sheep and deer were raised at the Glensaugh Research Station and were familiar with grazing heather moorland vegetation. The experiment was repeated in three fixed periods between June and July 1993 (1-6 June, 7- 21 June, 22 June - 6 July). In each period the three fragmentation patterns (ie 1, 4 and 12 grass patches) were grazed by the three groups of animals (Table 1). Alternate plots were always used (see Table 1), so as to isolate each animal group and prevent them from interacting with animals in other plots.

\section{Site B}

In this site the influence of mono-species (ie sheep or deer) or multi-species grazing (ie sheep + deer) on the diet of both animal species was studied. This site comprised two blocks of three, 1 ha, deer-fenced plots. The vegetation of each plot consisted of heather containing small natural patches of bilberry, fragmented by natural mosaics of small patches of grass, ranging from approximately $1 \mathrm{~m}^{2}$ to $400 \mathrm{~m}^{2}$ in size, comprising mainly Agrostis capillaris although other species such as Deschampsia flexuosa, Festuca rubra and Anthoxantum odoratum also occurred in small proportions. The experimental design comprised one animal treatment (ie animal species grazing alone or mixed) with three levels, sheep, deer (mono-species grazing), sheep+deer (multi-species grazing) one of which was applied consistently to each plot. Six groups of animals were grazed as follows: 2 single groups of 8 red deer, 2 single groups of 12 sheep and 2 mixed groups of 6 sheep and 4 red deer (the ratio of red deer to sheep was 1:1.5, respectively, as in Site A). Animal density on each of the six plots was thus equivalent to 12 sheep/ha, with two replicate plots grazed by sheep, two by deer and two by sheep + deer. During the summer of 1992 ( 1 June to 1 August) the animals grazed the plots for 8 consecutive weeks, which

Table 1. Experimental design for Site A. Species: s - sheep, d - deer. Animal group is represented by subscripts.

\begin{tabular}{|c|c|c|c|c|c|c|}
\hline Block & 1 & 1 & 1 & 2 & 2 & 2 \\
\hline Plot & 1 & 2 & 3 & 4 & 5 & 6 \\
\hline Number of patches & 1 & 4 & 12 & 12 & 4 & 1 \\
\hline \multicolumn{7}{|l|}{ Period } \\
\hline 1 & - & $\mathrm{s}+\mathrm{d}_{2}$ & - & $\mathrm{s}+\mathrm{d}_{1}$ & - & $\mathrm{s}+\mathrm{d}_{3}$ \\
\hline 2 & $\mathrm{~s}+\mathrm{d}_{2}$ & - & $\mathrm{s}+\mathrm{d}_{3}$ & - & $\mathbf{s}+\mathrm{d}_{1}$ & - \\
\hline 3 & - & $\mathrm{s}+\mathrm{d}_{1}$ & - & $\mathrm{s}+\mathrm{d}_{3}$ & - & $\mathrm{s}+\mathrm{d}_{2}$ \\
\hline
\end{tabular}


were divided into three sampling periods for this study, 1 June - 19 June, 20 June - 10 July, 11 July 1 August. In 1993, the animals grazed the plots for 4 weeks at the beginning of the summer (1 June to 2 July) giving one sampling period and for another 4 weeks in late summer (1 August to 2 September) giving a second sampling period.

\section{Diet composition}

On Site A, for each herbivore species, faecal samples were collected from each plot at the end of each of the three sampling periods as follows. The plots were visually divided into two, and 8 random clumps of fresh pellets were collected from each half plot (one clump was one animal's defecation). The 8 clumps from each half plot were bulked, giving 2 bulked replicate samples per plot per species. The total number of samples was 36 . Samples were bulked because samples could not be identified for each particular animal and variation among animals was not taken into account. On Site B each plot was divided into quarters and 8 clumps of pellets per species were collected and bulked within each quarter plot at the end of each grazing period (three periods in 1992 and two periods in 1993). In 1992, the samples of each quarter plot were bulked into one composite sample per plot per species for each period, giving a total of 24 samples. In 1993, quarter plot samples were held separately giving 4 samples per plot per species for each period, with a total number of samples 64 .

The proportion of each plant category in the diet was estimated by the identification of 200 plant fragments (at 100x using a Nikon Labophot binocular microscope) in each faecal sample using the microhistological technique (see details in Sparks and Malechek 1968, Holechek 1982). A reference collection of the epidermis of the plant species found in the two experimental sites was made prior to the examination of the faecal samples. The plant species identified were grouped into two main categories: "shrubs" which include Calluna vulgaris and Vaccinium myrtillus and "grasses" which include all grass species, and other close families, such as Cyperaceae and Juncaceae, and occasional non-woody dicotyledoneous plants (forbs).

One of the limitations of using the microhistological technique is that errors in quantification can arise when the components of the diet vary widely in the physical and digestive characteristics, especially if forbs are included in the diet (Holechek and Gross 1982). In our study, forbs were uncommon in the plots. Generally, grasses are overestimated when present in mixed diets with shrubs (Bartolomé et al. 1995). However, the primary aim of our study was to compare the diets of sheep and deer in relation to fragmentation and grouping type (mono vs mixed), therefore, we considered that the possible differences in digestibility of some vegetation components between sheep and deer (Milne $e t$ al. 1978) should not significantly affect the main effects discussed here.

\section{Statistical analysis}

The proportion of each vegetation category (ie grass or shrub) in the diet is a "compositional" term, since the sum of the proportion of both categories will equal one (Elston et al. 1996). Obviously, these categories cannot be treated as independent in a statistical approach (Martin and Bateson 1993) and, therefore, we used log ratio analysis, whose principle is to replace the proportion of categories by logs of ratios of the proportions (generally refereed to log ratio analysis). For operational convenience and because of skew-symmetric property of the data (Elston et al. 1996) we allocated the proportion of grass in the diet to the numerator and the proportion of shrub in diet to the denominator [ie $\log _{10}$ (proportion of grass/proportion of shrub)]. All statistical tests were based on log ratio input values, but we have given statistical descriptives as percentages of grass in the diet, to aid understanding and to facilitate comparisons with other studies from the literature.

As both experiments were not balanced, or as some terms represented more than one source of variation in the data, we used the method of Restricted Maximum Likelihood (REML, Lawes Agricultural Trust 1993) analysis. We analysed the experiments of Site A and Site B independently. Within Site B we also analysed 1992 and 1993 data separately because the grazing periods were different between years. In Site A the model used for REML analysis was as follows: fixed effects were species ( 2 levels: sheep and deer), period (3 levels), fragmentation (3 levels: 1, 4 and 12 patches), with their interactions, and random effects were plots. In site B, 1992 and 1993 the fixed effects model included species, grouping type (2 levels: mono-species, multi-species groups), period (1992 three 
levels; 1993 two levels) with their interactions, with plots as a random effect. The Wald statistic, approximated to a $\chi^{2}$ distribution, was used to estimate the significance of differences between treatments. Because the Wald statistic is calculated ignoring terms fitted later in the model, the main effects were applied in different orders, we did not find differences in our conclusions with the order we have proposed above. Statistical analyses were performed using Genstat 5 for Windows release 4.1 statistical software package (Genstat 5 Committee 1993).

\section{Results}

\section{Site A}

Both species differed in the proportion of grass in their diets $(p<0.0001$; Table $2)$, the diet of sheep containing more grass $(73 \%)$ than did that of deer $(27 \%)$. There was a significant interaction between period and vegetation fragmentation $(p=$ 0.0028 ; Table 2). In early June, the proportion of grass in the diet of both species

Table 2. Effects of grazing period and vegetation fragmentation (1 patch, 4 patches and 12 patches) on the proportion of grass contained in the diets of sheep and deer. Data were analysed using Restricted Maximum Likelihood (see Material and methods for details).

\begin{tabular}{lccc}
\hline Fixed term & Wald statistic & df & $p$ \\
\hline Species & 391.1 & 1 & $<0.0001$ \\
Period & 19.7 & 2 & 0.0001 \\
Fragmentation & 5.1 & 2 & $\mathrm{~ns}$ \\
Species $\times$ period & 1.7 & 2 & $\mathrm{~ns}$ \\
Species $\times$ fragmentation & 5.8 & 2 & $\mathrm{~ns}$ \\
Period $\times$ fragmentation & 16.2 & 4 & 0.0028 \\
Species $\times$ period $\times$ fragmentation & 5.1 & 4 & $\mathrm{~ns}$ \\
\hline
\end{tabular}

Table 3. Mean log ratio predicted means of the proportion of grass in the diets of sheep and red deer (associated to the analysis of Table 2) in three periods throughout the summer 1993 and under three different conditions of vegetation fragmentation (Site A). Mean log ratio is the proportion of grass divided by the proportion of heather in the diet $\log _{10}$-transformed. Positive and negative values of log ratio mean the direction of the deviation from equal proportionality of grass and heather in the diet (see Statistical analysis section for more details). In brackets the proportion of grass in the diet. Effective df for comparisons between periods $=18$. SED is the standard error of differences for comparisons within rows and within columns. Comparisons within rows: means with different superscript are significantly different at $\alpha=0.05$. Comparisons within columns: means with different subscript are significantly different at $\alpha=0.05$.

\begin{tabular}{lcrrr}
\hline Fragmentation & 1 patch & 4 patches & 12 patches & SED \\
\hline Period & & & & \\
1-6 June & $-0.02^{\mathrm{a}}{ }_{\text {ab }}(49 \%)$ & $0.25^{\mathrm{b}}{ }_{\mathrm{a}}(62 \%)$ & $0.16^{\mathrm{ab}}{ }^{\mathrm{a}}(57 \%)$ & 0.099 \\
7-21 June & $0.10^{\mathrm{a}}{ }_{\mathrm{a}}(55 \%)$ & $-0.01^{\mathrm{a}}{ }_{\mathrm{b}}(49 \%)$ & $-0.21^{\mathrm{a}}{ }_{\mathrm{b}}(42 \%)$ & \\
22 June - 6 July & $-0.18^{\mathrm{a}}{ }_{\mathrm{b}}(42 \%)$ & $-0.04^{\mathrm{a}}{ }_{\mathrm{b}}(48 \%)$ & $-0.09^{\mathrm{a}}{ }_{\mathrm{b}}(46 \%)$ & \\
SED & 0.097 & & & \\
\hline
\end{tabular}


increased significantly only from the 1 patch up to the 4 patches vegetation fragmentation pattern ( $49 \%$ vs $62 \%, p<0.05$; Table 3$)$. In the middle of June, the proportion of grass remained similar between 1 patch and 4 patches, but dropped significantly from 4 patches to 12 patches ( $49 \%$ vs $42 \%$; Table 3 ). In early July, no variation in the proportion of grass in the diet between patches was detected $(p>$ 0.05 ; Table 3). A reduction of grass in the diet of both sheep and deer throughout the summer occurred consistently only in the plots with 4 and 12 patches of grass (Table 3 ). In the plots with 1 patch of grass the pattern was different, the proportion of grass in the diet increased then dropped significantly in middle June in relation to late June $(p<0.05$; Table 3$)$.

\section{Site B}

In 1992, the proportion of grass in the diet of sheep was higher than that found in the diet of deer ( $52 \%$ vs $46 \%$, respectively, $p=0.02$; Table 4 ). The proportion of grass in the diet of both deer and sheep did not vary when animals where grazing in mono-species or multi-species groups ( $48 \%$ vs $50 \%$, respectively; Table 4 ). Grazing period affected the proportion of grass in the diet of sheep and deer in the same fashion $(p<0.0001$; Table 4). Both species had a greater proportion of grass in their diets $(p<0.05)$ in early June $(58 \%)$ in comparison with middle June - early July $(44 \%)$ or late July $(45 \%)$.

In 1993, there was a significant interaction between animal species and grouping type $(p<0.0001)$. The analysis of the standard errors of difference showed that the proportion of grass in the diet of deer was not affected by grazing in a mono- or multi-species group ( $44 \%$ vs $43 \%$, respectively, $p>0.05$; Table 5), however, the diet of sheep contained a significantly higher proportion of grass when they grazed in multi-species groups than when they grazed in mono-species groups ( $52 \%$ vs $38 \%$, respectively, $p<0.05$; Table 5 ). Sheep and deer differed in the proportion of grass in their diets only when they were grazing in multi-species groups. In the multi-species groups, sheep had more grass in their diet than did

Table 4. Effects of grouping type (mono-species or multi-species) and grazing period on the proportion of grass contained in the diets of sheep and deer in 1992 and 1993 (Site B). See Table 2 for more details.

\begin{tabular}{|c|c|c|c|c|c|c|}
\hline \multirow{2}{*}{ Fixed term } & \multicolumn{3}{|c|}{1992} & \multicolumn{3}{|c|}{1993} \\
\hline & Wald statistic & df & $p$ & Wald statistic & df & $p$ \\
\hline Species & 5.7 & 1 & 0.02 & 11.4 & 1 & 0.0004 \\
\hline Grouping type & 0.3 & 1 & $\mathrm{~ns}$ & 6.8 & 1 & 0.01 \\
\hline Period & 36.2 & 2 & $<0.0001$ & 0.0 & 1 & ns \\
\hline Species $\times$ grouping type & 0.3 & 1 & ns & 14.9 & 1 & 0.0001 \\
\hline Species $\times$ period & 1.7 & 2 & ns & 0.0 & 1 & ns \\
\hline Grouping type $\times$ period & 4.2 & 2 & ns & 0.7 & 1 & $\mathrm{~ns}$ \\
\hline Species $\times$ grouping type $\times$ period & 1.1 & 2 & ns & 0.6 & 1 & ns \\
\hline
\end{tabular}


Table 5. Mean log ratio predicted means of the proportion of grass in the diets of sheep and red deer when animals are grazing in mono- or multi-species groups (grouping type) in the summer 1993 (Site B) (associated to the analysis of Table 4). Effective df for comparisons between periods $=53$. For more details see Table 3 .

\begin{tabular}{lcrc}
\hline Grouping type & Mono-species & Multi-species & SED \\
\hline Species & & & \\
Sheep & $-0.22^{\mathrm{a}}{ }_{\mathrm{a}}(38 \%)$ & $0.04^{\mathrm{b}}{ }_{\mathrm{a}}(52 \%)$ & 0.047 \\
Deer & $-0.11^{\mathrm{a}}{ }_{\mathrm{a}}(44 \%)$ & $-0.12^{\mathrm{a}}{ }_{\mathrm{b}}(43 \%)$ & \\
SED & 0.061 & & \\
\hline
\end{tabular}

deer $(52 \%$ vs $43 \%$, respectively, $p<0.05$; Table 5 ). In 1993 , grazing period had no effect on the proportion of grass in the diet of either sheep or deer (Table 4).

\section{Discussion}

Response to the fragmentation of grass patches within heather moorland

On Site A, the grass in the plots was arranged in three vegetation fragmentation patterns, each containing a similar ratio of the area of grass to heather (1:4). Overall, we found that sheep had a greater preference for grass, with a mean of $73 \%$ of grass in their diet, in comparison with only $27 \%$ for deer. Deer were, therefore, using both types of vegetation in relation to their availability, whereas sheep showed a positive selection for grass. This difference in diet composition between species may be related to the different levels of tolerance for the tannin in heather and/or allometric differences in body mass between species. There is evidence that the voluntary intake of heather by red deer is higher than that by sheep (Milne et al. 1978) when fed ad libitum. Robbins et al. (1987) have also shown that the addition of tannin-rich forage to a basal diet does not depress the digestibility of plant fibre by white-tailed deer Odocoileus virginianus to the same extent that it does in sheep.

No interaction was obtained between the diet of each species and vegetation fragmentation, which indicates that the diet of both species responded in a similar fashion to the vegetation fragmentation. However, different responses between species seem to occur when the complexity of the pattern of vegetation fragmentation increases (Site A cf Site B, see Conclusions).

In a previous experiment at the site A (Clarke et al. 1995a) in which sheep and red deer grazed in mono-species groups, grass patch fragmentation treatment did have an effect on the time sheep spent grazing in different communities; sheep spent less time feeding on grass patches in the plots with 12 patches than in the plots with either 1 or 4 patches, while deer spent similar amounts of time feeding in grass patches across all fragmentation treatments. However, the overall utilisation of heather was not different in plots grazed by either sheep or red deer (Clarke et al. 1995b). These authors hypothesised that the differences between the direct observation and the utilisation of heather resulted from animals not being observed 
at night, when sheep grazing preferences might have altered. The results of our experiment at Site A revealed that the variation in availability of grass and heather throughout the period studied interacts with the pattern of vegetation fragmentation. When the biomass of grass is high (early June) a greater proportion of grass is found in the diet of both species grazing the vegetation fragmentation pattern of 4 patches. This pattern offers a distribution of grass which allows movements throughout the whole plot with a maximum probability at encounter grass (if the animal's movement is considered to be uniformly distributed in the plot). In the second period, when the grass biomass had dropped, the proportion of grass in the diets of both species was less in the 12 patches pattern than in the 1 or 4 patches. In this pattern of vegetation fragmentation it seems wise for a herbivore to focus on exploiting the grass in the larger patches (1 and 4 vegetation fragmentation) rather than graze grass scattered all over the plot (12 vegetation fragmentation pattern). When the biomass of grass drops even more (end of the grazing period) there are no differences between sheep and deer in the use of grass and heather, because focusing grazing activity on grass is not rewarding in any pattern of vegetation fragmentation.

Recent developments in optimal foraging theory would suggest that as herbivores move from an aggregated to a fragmented food distribution, there would be an increase in the less profitable component in the diet (Farnsworth and Illius 1998). This occurs because the animal's intake rate is constrained by chewing the food between bites when the animal grazes on an aggregated food resource (processing limited) and constrained by searching for preferred food items (encounter limited) when grazing on a fragmented food resource. Therefore, where resources are more fragmented and animals move from processing to encounter limited conditions (sensu Spalinger and Hobbs 1992) increased amounts of the less preferred category would be expected to occur in the diet in order that the opportunity to maintain intake rate is not lost. From the results presented here for Site A, both sheep and deer have a preference for a mixed diet (Hofmann 1989), even though deer include more browse in their diet than do sheep, and neither appear to be encounter limited despite changes in fragmentation of the grass patch because the patches were of sufficient size to allow the animals to spend a foraging bout within one vegetation patch.

However, although on Site B the proportion of grass and heather in the plots was similar to that on Site A, the mosaic was much more complex, with $>100$ grass patches of a range of sizes per plot, most of which were considerably smaller than those in Site A. On Site B sheep and deer appeared to have a different foraging strategy from that exhibited in Site A. Overall sheep still had more grass in their diet than did deer ( $52 \%$ vs $46 \%$ ), however, in comparison to Site A, sheep consumed less grass in Site B and deer consumed more grass. Behavioural observations of the sheep and deer in Site B also showed a slightly higher proportion of time spent grazing grass by sheep than by deer (60\% vs $47 \%$ ) (Hester et al. 1999). The natural fragmentation of grass into smaller patches on Site B resulted in the sheep moving through heather more often to access grass patches than in the less fragmented 
grass patches of Site A (Hester et al. 1999), which suggests that with the high levels of grass patch fragmentation in Site B sheep had become encounter-limited (cf Site A). Deer also appear to be encounter limited but favoured the consumption of grass rather than heather when the complexity of vegetation fragmentation increases.

\section{Response to mixed grazing}

The presence of other animal species can play an important part in decision making about diet, patch and habitat choice for herbivores (Gordon and Illius 1989). Where resource availability is high, competition is likely to be low, whereas when resources are limited, both direct and indirect competitive interactions are likely to be more severe.

On Site B in 1992, there were no differences in diets between multi- and mono-specific treatments for either species. On Site B in 1993, the proportion of grass in the diet was similar between species when they were grazing in mono-species groups but the diet differed between species in the multi-species group, with sheep ingesting a greater proportion of grass. In this experiment (Site B) the stocking densities were equivalent across treatments, therefore, in mixed grazing plots the intraspecies competition in sheep was less than in plots grazed by sheep alone ( 6 sheep in multi-species groups versus 12 sheep in mono-species groups). As a consequence, there may be greater competition between sheep than between sheep and red deer at the equivalent overall stocking density. It should be noted that the preference of sheep is for a mixed diet dominated by grasses whereas as deer tend to prefer a mixed diet dominated by browse (Hofmann 1989 and Site A) and grass was in relatively short supply compared to heather. The fact that the change in diet with grouping type held for 1993 but not for 1992 may reflect the additional influence of declining grass availability through the sample periods in 1992 (from 8 to $3 \mathrm{~cm}$ ) as compared to short sward at both sample periods in $1993(3.8 \mathrm{~cm})$.

In the experiment conducted on Site A, the total biomass of vegetation available per animal was greater than on Site B because the animal density was lower and the height of heather taller (Clarke et al. 1995b, Hester and Baillie 1998). Under such conditions, sheep and red deer showed resource partitioning (the diet of sheep contained mainly grasses and the diet of red deer mainly heather) which presumably decreased the likelihood of direct competition (Jarman and Sinclair 1979, Gordon and Illius 1989).

The results of our experiments do not support the observational evidence that wild red deer feed more on heather dominated communities in the presence of sheep than when grazing alone (Osborne 1984). The difference between the current experiment and the wild situation is considered unlikely to be because the resource availability on grass patches on Site B was sufficient to sustain deer by the end of the experiment, because the grass sward heights dropped to around $3 \mathrm{~cm}$ by the end of all of the experimental periods (Hester and Baillie 1998) which is below the optimum threshold for maintenance of intake in red deer (Illius and Gordon 1987). A more feasible explanation is that the small scale nature of this experiment 
precluded red deer from moving to other parts of the landscape to avoid the disturbance associated with normal sheep husbandry (ie being gathered by man and dog) in the wild context. This phenomenon may be a prime determinant of segregation between livestock and wildlife.

\section{Temporal changes in diet}

There is evidence from a grass/heather community experiment with single large blocks of grass and heather, that the proportion of heather in the diet of sheep was negatively related to the grass sward height (Milne and Grant 1987). Our results show a decrease in the proportion of grass in the diet of both species from the first period in comparison with the second and third periods in the vegetation fragmentation of 4 and 12 patches, however, a different pattern was detected in the 1 patch plots, which is difficult to explain. In the experiment on Site A, the sward height decreased from 7 to $5 \mathrm{~cm}$ between 6 June and 6 July (I. Hulbert, unpubl.) which may have caused the increase in heather content in the diets of the sheep and red deer. Alternatively or additionally, the changes in diet composition may result from the relative changes in the quality of grass and heather over the season (Armstrong et al. 1997). Grass quality decreases through season whereas heather declines also but less, so difference in relative nutritional value between grass and heather decreases (Armstrong et al. 1986).

On Site B, the reduction in the proportion of grass in the diets of both sheep and red deer throughout the summer in 1992 may also have been related to the decline in grass height between early June $(8 \mathrm{~cm})$ and early August $(3 \mathrm{~cm})$. Behavioural observations showed that in line with the dietary data, there was a trend for both species to increase their proportional grazing time on heather as grass sward heights decreased (Hester et al. 1999). However, in 1993, grass heights did not differ at the end of both experimental periods when the samples were collected (sward height $3.8 \mathrm{~cm}$ at the end of each 4 weeks grazing period) which presumably explains why no period difference in diet composition was found in 1993.

\section{Conclusions}

When both Sites are compared, a decrease in the proportion of the grass category in the diet of sheep appears to occur when the complexity of the pattern of the patch distribution and vegetation fragmentation increases [ie regular patch distribution and small number of patches (1-12) in Site A in comparison with random distribution and high number of patches $(\sim 100)$ in Site B]. The opposite pattern was detected in deer, that is the proportion of grass in their diet increased when the complexity of the pattern increased. This may reflect the differences in the frequency with which deer encountered grass patches on the two experiments, in view of the fact that deer strongly prefer to rest in heather, unlike sheep (Clarke et al. 1995a, Hester et al. 1999). The greater distances between grass patches in Site A in comparison with Site B $(>30 \mathrm{~m}$ as against $<10 \mathrm{~m}$, Clarke et al. 1995a and A. 
Hester, unpubl.), possibly reduced the encounter rate of grass patches for deer in Site A because of their choice of resting location.

In conclusion, the diets of sheep and deer were apparently not affected by the fragmentation of the grass patches when patches were few and distributed in a regular pattern. However, the diets of sheep and deer did change when grass patches were highly fragmented (cf Site A and Site B). The diet of deer was not affected by the presence of sheep, contrary to previous suggestions by Osborne (1984). The results suggest that the observations of sheep and red deer occupying different vegetation communities when feeding in free-ranging situations may result from red deer avoiding the disturbance associated with sheep husbandry rather than due to any direct or indirect competitive effects between the species.

Acknowledgements: We are grateful to Mr G. Baillie for his help in faecal collection. Financial support for this study was provided by the Agriculture and Food Research Council's Joint Agricultural and Environment Programme (JAEP) and the Scottish Executive Rural Affairs Department. PC and FJP-B were financed by the Training and Mobility of Researchers Scheme of the European Communities. Dr J. A. Milne kindly commented on the manuscript.

\section{References}

Armstrong H. M., Gordon I. J., Sibbald A. R., Grant S. A., Hutchings N. J. and Milne J. A. 1997. A model of grazing by sheep on hill systems in the U.K. I. The prediction of vegetation biomass. Journal of Applied Ecology 34: 166-185.

Armstrong R. H., Common T. G. and Smith H. K. 1986. The voluntary intake and in vivo digestibility of herbage harvested from indigenous hill plant communnities. Grass and Forage Science 41: 53-60.

Bartolomé T., Franch T., Gutman M. and Seligman N. G. 1995. Physical factors that influence fecal analysis estimates of herbivore diets. Journal of Range Management 48: 267-270.

Bullock D. J. 1985. Annual diets of hill sheep and feral goats in southern Scotland. Journal of Applied Ecology 22: 423-433.

Clarke J. L., Welch D. and Gordon I. J. 1995a. The influence of vegetation pattern on the grazing of heather moorland by red deer and sheep. I. The location of animals on grass/heather mosaics. Journal of Applied Ecology 32: 166-176.

Clarke J. L., Welch D. and Gordon I. J. 1995b. The influence of vegetation pattern on the grazing of heather moorland by red deer and sheep. II. The impact on heather. Journal of Applied Ecology 32: 177-186.

Colquhoun I. R. 1970. The grazing ecology of red deer and blackface sheep in Perthshire, Scotland. $\mathrm{Ph}$ D thesis, University of Edinburgh, Edinburgh, U.K.

Demment M. W. 1982. The scaling of ruminoreticulum size with body-weight in East African ungulates. African Journal of Ecology 20: 43-47.

Elston D. A., Illius A. W. and Gordon I. J. 1996. Assessment of preference among a range of options using log ratio analysis. Ecology 77: 2538-2548.

Farnsworth K. D. and Illius A. W. 1998. Optimal diet choice for large herbivores: an extended contingency model. Functional Ecology 12: 74-81.

Fraser M. D. and Gordon I. J. 1997. The diet of goats, red deer and South American camelids feeding on three contrasting Scottish upland vegetation communities. Journal of Applied Ecology 34: 668-686.

Genstat 5 Committee 1993. Genstat 5 release 3 reference manual. Clarendon Press, Oxford: 1-796.

Gordon I. J. 1989. Vegetation community selection by ungulates on the Isle of Rhum. II. Vegetation community selection. Journal of Applied Ecology 26: 53-64.

Gordon I. J. and Illius A. W. 1989. Resource partitioning by ungulates on the Isle of Rhum. Oecologia 79: 383-389.

Gwynne M. D. and Bell R. H. V. 1968. Selection of vegetation components by grazing ungulates in the Serengeti National Park. Nature 220: 390-393. 
Hester A. J. and Baillie G. J. 1998. Spatial and temporal patterns of heather use by sheep and red deer within natural heather/grass mosaics. Journal of Applied Ecology 35: 772-784.

Hester A. J., Gordon I. J., Baillie G. J. and Tappin E. 1999. Foraging behaviour of sheep and red deer within natural heather grass mosaics. Journal of Applied Ecology 36: 133-146.

Hofmann R. R. 1989. Evolutionary steps of ecophysiological adaptation and diversification of ruminants: a comparative view of their digestive system. Oecologia 78: 443-457.

Holechek J. L. 1982. Sample preparation technique for microhistological analysis. Journal of Range Management 35: 267-268.

Holechek J. L. and Gross B. 1982. Training needed for quantifying simulated diets from fragmented range plants. Journal of Range Management 35: 644-647.

Illius A. W. and Gordon I. J. 1987. The allometry of food intake in grazing ruminants. Journal of Animal Ecology 56: 989-999.

Jarman P. J. 1974. The social organisation of antelope in relation to their ecology. Behaviour 48: $215-266$.

Jarman P. J. and Sinclair A. R. E. 1979. Feeding strategy and the pattern of resource partitioning in ungulates. [In: Serengeti: dynamics of an ecosystem. A. R. E. Sinclair and M. Norton-Griffiths, eds]. University of Chicago Press, Chicago: 130-163.

Lawes Agricultural Trust. 1993. Genstat 5 release 3 reference manual. Oxford University Press, Oxford: 1-796.

Martin P. and Bateson P. 1993. Measuring behaviour: An introductory guide. 2nd edition. Cambridge University Press, Cambridge: 1-222.

McNaughton S. J. 1991. Evolutionary ecology of large tropical herbivores. [In: Plant-animal interactions: Evolutionary ecology in tropical and temperate regions. P. W. Price, T. M. Lewinsohn, G. W. Fernandes and W. W. Benson, eds]. John Wiley \& Sons, Inc., New York: 509-520.

Milne J. A. and Grant S. A. 1987. Sheep management on heather moorland. [In: Efficient Sheep Production. Occasional Symposium of the British Grassland Society No 21. G. E. Pollott, ed]. The Lavenham Press, Lavenham, Suffolk: 165-167.

Milne J. A., Macrae J. C., Spence A. M. and Wilson S. 1978. A comparison of the voluntary intake and digestion of a range of forages at different times of the year by the sheep and the red deer Cervus elaphus. British Journal of Nutrition 40: 347-356.

Osborne B. C. 1984. Habitat use by red deer (Cervus elaphus L.) and hill sheep in the West Highlands. Journal of Applied Ecology 21: 497-506.

Robbins C. T., Mole S., Hagermann A. E. and Hanley R. T. 1987. Role of tannins in defending plants against ruminants: reduction in dry matter digestibility? Ecology 68: 1606-1615.

Senft R. L., Coughenour M. B., Bailey D. W., Rittenhouse L. R., Sala O. E. and Swifi D. M. 1987. Large herbivore foraging and ecological hierarchies. Bioscience 37: 789-799.

Spalinger D. A. and Hobbs N. T. 1992. Mechanisms of foraging in mammalian herbivores: new models of functional response. The American Naturalist 140: 325-348.

Sparks D. R. and Malechek J. C. 1968. Estimating percentage dry weight in diets using a microscope technique. Journal of Range Management 21: 264-265.

Sydes C. and Miller R. 1988. Range management and nature conservation in the Brithis Uplands. [In: Ecological change in the uplands. M. B. Usher and D. B. A. Thompson, eds]. British Ecological Society, Special Publication Series No 7: 323-337.

Van Soest P. J. 1996. Allometry and ecology of feeding-behavior and digestive capacity in herbivores a review. Zoo Biology 15: 455-479.

Welch D. 1984. Studies in the grazing of heather moorland in north-east Scotland. I. Site descriptions and patterns of utilization. Journal of Applied Ecology 21: 179-195.

Wiens J. A. 1985. Vertebrate responses to environment patchiness in arid and semi-arid ecosystems. [In: The ecology of natural disturbance and patch dynamic. S. T. A. Pickett and P. S. White, eds]. Academic Press, London, New York: 169-192.

Received 20 August 1999, accepted 17 January 2000. 